\title{
Potential estimation of major mineral contents in cow milk using mid-infrared spectrometry
}

\author{
H. Soyeurt, ${ }^{\star 1}$ D. Bruwier, ${ }^{*}$ J.-M. Romnee, $\dagger$ N. Gengler, ${ }^{\star} \ddagger$ C. Bertozzi,§ D. Veselko,\# and P. Dardenne† \\ *Gembloux Agricultural University, Animal Science Unit, B-5030 Gembloux, Belgium \\ †Walloon Agricultural Research Centre, Quality Department, B-5030 Gembloux, Belgium \\ $\ddagger$ National Fund for Scientific Research, B-1000 Brussels, Belgium \\ §Walloon Breeding Association, B-5590 Ciney, Belgium \\ \#Milk Committee, B-4651 Battice, Belgium
}

\section{ABSTRACT}

Milk and dairy products are a major source of minerals, particularly calcium, involved in several metabolic functions in humans. Currently, several dairy products are enriched with calcium to prevent osteoporosis. The development of an inexpensive and fast quantitative analysis for minerals is required to offer dairy farmers an opportunity to improve the added value of the produced milk. The aim of this study was to develop 5 equations to measure $\mathrm{Ca}, \mathrm{K}, \mathrm{Mg}, \mathrm{Na}$, and $\mathrm{P}$ contents directly in bovine milk using mid-infrared (MIR) spectrometry. A total of 1,543 milk samples were collected between March 2005 and May 2006 from 478 cows during the Walloon milk recording and analyzed by MIR spectrometry. Using a principal component approach, 62 milk samples were selected by their spectral variability and separated in 2 calibration sets. Five outliers were detected and deleted. The mineral contents of the selected samples were measured by inductively coupled plasma atomic emission spectrometry. Using partial least squares combined with a repeatability file, 5 calibration equations were built to estimate the contents of $\mathrm{Ca}, \mathrm{K}, \mathrm{Mg}, \mathrm{Na}$, and $\mathrm{P}$ in milk. To assess the accuracy of the developed equations, a full cross-validation and an external validation were performed. The cross-validation coefficients of determination $\left(\mathrm{R}^{2} \mathrm{cv}\right)$ were 0.80 , 0.70 , and 0.79 for $\mathrm{Ca}, \mathrm{Na}$, and $\mathrm{P}$, respectively ( $\mathrm{n}=$ 57 ), and 0.23 and 0.50 for $\mathrm{K}$ and $\mathrm{Mg}$, respectively (n $=31$ ). Only $\mathrm{Ca}$, Na, and $\mathrm{P}$ equations showed sufficient $\mathrm{R}^{2} \mathrm{cv}$ for a potential application. These equations were validated using 30 new milk samples. The validation coefficients of determination were $0.97,0.14$, and 0.88 for $\mathrm{Ca}, \mathrm{Na}$, and $\mathrm{P}$, respectively, suggesting the potential to use the $\mathrm{Ca}$ and $\mathrm{P}$ calibration equations. The last 30 samples were added to the initial milk samples and the calibration equations were rebuilt. The $\mathrm{R}^{2} \mathrm{cv}$ for

Received September 20, 2008.

Accepted January 20, 2009.

${ }^{1}$ Corresponding author: soyeurt.h@fsagx.ac.be
$\mathrm{Ca}, \mathrm{K}, \mathrm{Mg}, \mathrm{Na}$, and $\mathrm{P}$ were $0.87,0.36,0.65,0.65$, and 0.85 , respectively, confirming the potential utilization of the Ca and P equations. Even if new samples should be added in the calibration set, the first results of this study showed the feasibility to quantify the calcium and phosphorus directly in bovine milk using MIR spectrometry.

Key words: milk, mineral, mid-infrared spectrometry, calcium

\section{INTRODUCTION}

Milk and dairy products are the main source of calcium (around 1,200 mg/L of milk) in Western diets (Devriese et al., 2006). In Belgium, cheese is the major source of calcium (27\%) followed by raw milk (14\%). Globally, dairy products contribute $54 \%$ of the daily dietary intake of calcium (Devriese et al., 2006). In the European Union, this contribution varies between 45 and $70 \%$ (Guéguen and Pointillart, 2000). According to Gerrior and Bente (2002), milk provides more than $70 \%$ of the calcium available in the US food supply.

Consumption of the multifunctional nutriment calcium is important for humans because calcium plays a role in several metabolic functions such as blood coagulation and muscular contractions. The average recommended dietary calcium intake is about $900 \mathrm{mg} / \mathrm{d}$ for adults (19 to $59 \mathrm{yr}$ old) and 1,200 mg/d for adolescents and the elderly (Guéguen and Pointillart, 2000; Devriese et al., 2006). However, consumption of Ca by women and men is too low. In Belgium, in 2004, the average consumption of dietary calcium was $838 \mathrm{mg} / \mathrm{d}$ for men and $716 \mathrm{mg} / \mathrm{d}$ for women (e.g., Heaney, 2000; Devriese et al., 2006). According to Huth et al. (2006), the low intake of calcium by Americans and the large difference between recommended and typical dietary $\mathrm{Ca}$ intakes are recognized as major public health problems. In fact, low consumption of $\mathrm{Ca}$ has several effects on human health such as osteoporosis, which is more frequent in women than in men (e.g., Guéguen and Pointillart, 2000; Lanou et al., 2005; Devriese et al., 2006; Huth et 
al., 2006), arterial hypertension, colon cancer (Guéguen and Pointillart, 2000; Huth et al., 2006), and regulation of body weight and body fat (Huth et al., 2006).

Milk is a good source of other major minerals such as magnesium, phosphorus, and potassium. In the United States, dairy products provide about $16 \%$ of $\mathrm{Mg}$ and $32 \%$ of $\mathrm{P}$ and $\mathrm{Na}$ dietary intakes. Like calcium, phosphorus and magnesium are involved in bone health and human development. The combination of sodium, magnesium, calcium, and other milk components such as vitamins, protein, and essential fatty acids has a beneficial effect on blood pressure regulation (Huth et al., 2006).

Currently, several dairy products are enriched in calcium to prevent osteoporosis. However, according to Huth et al. (2006), the combination of minerals in milk seems to be more effective than minerals taken alone. Improving the mineral content in milk could be an interesting opportunity for dairy farmers to add value to the milk produced. To do this, the farmers could use the natural sources of variation influencing the contents of mineral in milk. For instance, Mouillet et al. (1975) and Cerbulis and Farrell (1976) showed breed differences for the mineral profile in bovine milk. Davis et al. (2001) observed within-breed differences of calcium for constant protein content in milk, suggesting a potential animal selection effect on mineral contents. The use of genetic variation (within or across breeds) requires a large data set. Currently, one of the faster methodologies - inductively coupled plasma atomic emission spectrometry (ICP-AES) - is too expensive to permit routine analysis of milk samples collected, for instance, during the regular milk recording managed by different breed organizations. However, the regular milk recording permits the rapid collection of a large amount of data. The current method used to measure the contents of fat, protein, lactose, and urea during regular milk recording is mid-infrared (MIR) spectrometry. Using this technology to measure the contents of mineral in milk could permit the development of selection and management tools for dairy farmers to improve the nutritional quality of milk. Thus, the objective of this research was to study the feasibility of developing calibration equations permitting the quantification of $\mathrm{Ca}, \mathrm{K}, \mathrm{Mg}, \mathrm{Na}$, and $\mathrm{P}$ directly in bovine milk using MIR spectrometry.

\section{MATERIALS AND METHODS}

\section{Sampling and Recording Spectra Files}

The development of calibration equations requires the analysis of samples showing a large variability of milk composition. Therefore, different known sources of variation for milk composition were taken into account during the sampling (e.g., geographical situation, season of sampling, breed). Following standard procedures (International Committee for Animal Recording, 2004), $2 \times 1,543$ milk samples of $50 \mathrm{~mL}(50 \%$ morning milk and $50 \%$ evening milk) were collected for $1 \mathrm{yr}$ (March 2005 to May 2006) during the milk recording of the Walloon region of Belgium organized by the Walloon Breeding Association (Ciney, Belgium). These samples were collected from 478 cows belonging to 8 herds and representing 6 dairy breeds (dual-purpose Belgian Blue, Holstein-Friesian, Jersey, Montbeliarde, Normande, and Meuse-Rhine-Yssel type Red and White). One sample was analyzed directly after sampling by MIR spectrometry using a MilkoScan FT6000 spectrometer (Foss, Hillerød, Denmark) by the Milk Committee (Battice, Belgium). All of the generated spectra were recorded in a database. The second sample was conserved at $-26^{\circ} \mathrm{C}$ pending chemical analysis.

\section{Selection of Samples}

The measurement of mineral contents for all collected samples was not conceivable because of the cost of chemical analysis. The selection of samples was difficult because any indicator traits of mineral contents in milk were available. To maximize the milk composition variability of the samples used in the calibration set, 100 samples were selected from their spectral variability using a principal components approach.

\section{Reference Method}

The reference mineral contents used for the calibration process were measured using ICP-AES (Ultima, JobinYvon, Longjumeau, France). The dispersive system was a Czerny-Turner monochromator; the focal distance was $1 \mathrm{~m}$. A concentric nebulizer composed of Meinhard glass and a cyclonic room was used. The spectral data ranged from 120 to $800 \mathrm{~nm}$. Humidification of argon was used as well as a peristaltic pump. The integration parameters were as follows: nebulizer gas flow $=0.75$ $\min ^{-1} ;$ pressure of nebulizer $=3$ bar; Rf power $=1,100$ $\mathrm{W}$; fixed time of rising $=60 \mathrm{~s}$; fast speed rinsing pump; time of transfer $=15 \mathrm{~s}$; time of stabilization $=45 \mathrm{~s}$; fast speed of transfer pump; synchronization time $=0 \mathrm{~s}$; normal speed of pump $=20 \mathrm{~m} / \mathrm{s}$. The spectral lines for the detection of $\mathrm{Ca}, \mathrm{K}, \mathrm{Mg}, \mathrm{Na}$, and $\mathrm{P}$ were 318,766 , 279, 590, and $178 \mathrm{~nm}$, respectively.

Some liquids can be analyzed without the mineralization stage (which increases the cost of analysis, the time needed, and, frequently, the risk of sample contamination). Nobrega et al. (1997) tested the direct analysis of milk without mineralization using a dilution in an 
aqueous solution at $\mathrm{pH} 8$ containing a tertiary amine mixed at 5 and $10 \%$ to prevent the precipitation of proteins. Murcia et al. (1999) performed direct analysis of diluted milk samples (1:50) by addition of Fluka Triton X-100 (polyethylene glycol tert-octylphenyl ether; Sigma-Aldrich, Birnem, Belgium) as a tensioactive dispersant to improve the repeatability of measurements. The results obtained with and without mineralization stage were similar (Murcia et al., 1999).

Before the development of calibration equations, the first step of this study was to validate the hypothesis that the measurements of minerals by ICP-AES with and without a previous mineralization stage should be similar. Four milk samples were chosen based on their extreme fat content $(2.38,2.40,7.52$, and 7.62 $\mathrm{mg} / \mathrm{dL}$ of milk) because fat is a critical point in milk analysis by ICP-AES. These selected samples were then analyzed by ICP-AES with and without the mineralization stage. Each sample was analyzed 3 times for each treatment. For the dispersive analysis, each sample was diluted at 1:100 and Triton X-100 was added at 1:1000. The diluent was ultra-pure water obtained with a MilliQ Gradient instrument (Millipore, Billerica, MA). A nitroperchloric mineralization by microwave was used. A total of $0.5 \mathrm{~g}$ of sample was introduced in a Teflon vessel. Then, $1 \mathrm{~mL}$ of $\mathrm{H}_{2} \mathrm{O}_{2}$ at $30 \%$ (Merck, Brussels, Belgium) and $6 \mathrm{~mL}$ of $\mathrm{HNO}_{3}$ at $65 \%$ (Merck) were added. The vessel was hermetically sealed and placed in the microwave. Two microwaves (MLS 1200 mega, Milestone Microwave Laboratory Systems, Bergamo, Italy) were used. The first contained a rotor with 6 places and the second had a rotor with 10 places. The process of mineralization using the microwave containing a rotor with 6 places was 1 min at $250 \mathrm{~W} ; 1$ min at $0 \mathrm{~W} ; 5$ min at $250 \mathrm{~W} ; 5 \mathrm{~min}$ at $400 \mathrm{~W} ; 5$ min at $650 \mathrm{~W}$; and $10 \mathrm{~min}$ of ventilation. The process of mineralization using the microwave containing a rotor with 10 places was: 2 min at $250 \mathrm{~W} ; 2$ min at $0 \mathrm{~W} ; 5$ min at 250 $\mathrm{W} ; 5$ min at $450 \mathrm{~W} ; 5$ min at $650 \mathrm{~W} ; 5$ min at $450 \mathrm{~W}$; and $10 \mathrm{~min}$ of ventilation. The dispersed samples were analyzed first followed by the mineralized samples to prevent potential precipitation of proteins. After mineralization, the samples were filtered using Whatman filter paper (595 1/2, diameter $125 \mathrm{~mm}$, Scheider and Schuell, Dassel, Germany). For the filtration of samples for the quantification of $\mathrm{P}$, a paper poor in $\mathrm{P}$ was used (Whatman, 512 1/2, diameter $150 \mathrm{~mm}$, Scheicher and Schuell).

\section{Estimation of Uncertainty}

The uncertainty of measurement comprised different sources of uncertainty: 1) the uncertainty of repeatability among independent analyses executed on the same sample $\left.\left(\mathrm{U}_{\text {repeat }}\right) ; 2\right)$ the uncertainty about the recovery percentage of mineral element estimated using a certified reference milk (CRM) sample ( $\left.\mathrm{U}_{\text {recup }}\right) ; 3$ ) the uncertainty on the weighing of sample $\left(\mathrm{U}_{\text {weight }}\right)$. The calibration certificate of the precision balance provided this information; 4) the uncertainty of the dilutions of the sample $\left(\mathrm{U}_{\text {dilution }}\right)$. The manufacturer of the vessel mentioned this characteristic; 5) the uncertainty of the ICP-AES instrument $\left(\mathrm{U}_{\mathrm{ICP}}\right)$. The instrument gave this uncertainty from repeated analysis (3 times) of the sample milk sample; 6 ) the uncertainty of the concentration of the stock solution [standard solution: CertiPur (Merck) for the standard needed for the calibration of the ICP-AES instrument $\left.\left(\mathrm{U}_{\text {stock }}\right)\right]$. The manufacturer provided this information; 7) the uncertainty of the dilutions of the standard needed to establish the calibration of the ICP-AES instrument ( $\left.\mathrm{U}_{\text {standard }}\right)$; and finally, 8) the uncertainty about the purity of the CRM sample used $\left(\mathrm{U}_{\mathrm{CRM}}\right)$. The provider gave this characteristic.

The CRM sample used was a powdered skimmed milk (CRM-063R) of the Community Bureau of Reference (Brussels, Belgium). In accordance with Skoog et al. (1997), the total uncertainty of the chemical method $\left(\mathrm{U}_{\text {total }}\right)$ was calculated following this expression:

$$
\mathrm{U}_{\text {total }}=\sqrt{\begin{array}{l}
\left(\mathrm{U}_{\text {repeat }}\right)^{2}+\left(\mathrm{U}_{\text {recup }}\right)^{2}+\left(\mathrm{U}_{\text {weight }}\right)^{2}+\left(\mathrm{U}_{\text {dilution }}\right)^{2} \\
+\left(\mathrm{U}_{\text {ICP }}\right)^{2}+\left(\mathrm{U}_{\text {stock }}\right)^{2}+\left(\mathrm{U}_{\text {standard }}\right)^{2}+\left(\mathrm{U}_{\mathrm{CRM}}\right)^{2}
\end{array}} .
$$

\section{Calibration Procedure}

The calibration equations were established using 3 different calibration sets. The first calibration set contained the 40 samples showing the highest spectral variability from the 100 samples initially selected. Eight samples were not correctly conserved and were not analyzed by ICP-AES. Following the same approach, a second set including 30 samples was created from the 60 remaining samples. The third calibration set contained 30 samples selected using the Ca calibration equation developed based on the samples contained in the first and the second calibration sets (more details in the Results and Discussion section). A total of 92 samples were analyzed by ICP-AES; 5 outliers were detected and deleted. From the reference mineral contents and the corresponding spectral data, 5 calibration equations for the prediction of $\mathrm{Ca}, \mathrm{K}, \mathrm{Mg}, \mathrm{Na}$, and $\mathrm{P}$ contents were developed using a program for multivariate calibration (WINISI III; http://www.winisi.com/; Foss, Hillerød, Denmark). The use of partial least squares regressions was preferred in this study over other methods such as multiple linear or principal components regressions because the use of partial least squares regressions limits the presence of noise in the calibration equations 
when a limited number of samples are used. In fact, the PLS method compresses all spectral data (Martens and Jensen, 1982; Frank et al., 1984) and simultaneously maximizes the variability of the dependent variable (Martens and Naes, 1987).

To linearize the spectra, the initial spectral data expressed in transmittance were converted into absorbance using the following formula: absorbance $=$ $\log \left(\right.$ transmittance $\left.^{-1}\right)$.

To improve the repeatability of the calibration equations across instruments, a repeatability file containing milk spectra analyzed by 4 different MilkoScan FT6000 (Foss) was used: 3 located at the Milk Committee (Battice, Belgium) and 1 located at Convis (Ettelbruck, Luxembourg). The approach was similar to the one described by Westerhaus (1990). Some statistical parameters of the developed calibration equations were calculated to assess the accuracy of the prediction: the mean and the standard deviation (SD) of the reference mineral contents measured by ICP-AES, the standard error of calibration (SEC), and the calibration coefficient of determination $\left(\mathbf{R}_{\mathbf{C}}{ }^{2}\right)$.

\section{Validation}

The developed calibration equations were validated using 2 different methods: an internal validation using a full cross-validation and an external validation using milk samples that were not used to build the considered equations.

A full cross-validation was applied to determine the most appropriate number of factors used and also to assess the robustness of the developed equations. Crossvalidation uses the same samples for validation and calibration processes. Full cross-validation leaves out one sample and then performs a calibration with the remaining samples (Williams, 2007). This procedure is repeated until every sample has been predicted once. Finally, the validation errors are combined into a standard error of cross-validation (SECV). Consequently, some additional statistical parameters were calculated to assess the accuracy of calibration equations: the SECV and the cross-validation coefficient of determination $\left(\mathbf{R}^{2}{ }_{\mathbf{C V}}\right)$. The ratio of SECV to SD (RPD) was also calculated to assess the efficiency of the calibration (Williams, 2007).

External validation was based on the comparison between the mineral contents predicted by MIR spectrometry and those measured by the reference chemical analysis (ICP-AES) for milk samples that were not used for the calibration procedure. The prediction values were obtained by applying the developed calibration equations on collected spectra using the calibration program (WINISI III; http://www.winisi.com/; Foss).
The validation coefficient of determination $\left(\mathbf{R}^{2} \mathbf{v}\right)$ was calculated.

\section{RESULTS AND DISCUSSION}

\section{Reference Method}

Table 1 depicts the results obtained for the analysis by ICP-AES of the 4 selected samples with and without the mineralization pretreatment. This experiment showed that these 2 treatments (with and without mineralization) differed significantly only for K. Indeed, the $P$-value obtained by the test of equality of means and presented in Table 1 was $<0.001$ for $\mathrm{K}$. The coefficient of variation $(\mathbf{C V})$ observed from the measurement of $\mathrm{Na}$ by direct milk dispersion in the ICP-AES spectrometer was greater than that calculated for the measurement of $\mathrm{Na}$ after mineralization. Thus, the direct analysis of milk sample by ICP-AES was not appropriate to measure the Na content. However, in accordance with the CV values, the direct analysis of milk by ICP-AES was more efficient for the measurement of the other studied minerals (Table 1).

This observation was confirmed by the coefficient of determination $\left(\mathrm{R}^{2}\right)$ calculated for the relationships between the mineral concentrations measured by ICPAES with and without mineralization. In fact, $\mathrm{R}^{2}$ was 0.99 for $\mathrm{Ca}, \mathrm{Mg}$, and $\mathrm{P}$, and was 0.95 for $\mathrm{K}$. The $\mathrm{R}^{2}$ value for $\mathrm{Na}$ was the lowest (0.92), indicating the larger difference in the measurement of $\mathrm{Na}$ between the 2 studied methods. However, this value was still relatively high.

The average differences for the mineral contents measured by the 2 considered methods are also presented in Table 1. The difference ranged between 7.8 and $15.2 \%$. As expected based on the previous results, the greatest difference was observed for Na. Globally, the values given by the direct analysis of milk sample were greater than those measured after a mineralization stage.

For the 2 methods, the repeatability can be considered as good because the CV values were $\leq 3 \%$ except for the measurement of $\mathrm{Na}$ performed by ICP-AES without previous mineralization (Table 1).

This inequality between the concentrations obtained by ICP-AES with and without mineralization was in agreement with a previous study conducted by Roulez (2001). The results obtained by that author showed the highest contents of $\mathrm{Ca}, \mathrm{K}$, and $\mathrm{Na}$ for the direct method of analysis compared with the mineralization pretreatment. The use of nitric acid could precipitate a part of the proteins and modify the spatial repartition of mineral in the solution. The use of Triton X-100 was not investigated. In contrast to the results of Roulez (2001), Murcia et al. (1999) used this tensioactive dispersant and showed similar results with and without 
Table 1. Comparison between the concentrations of studied minerals (means and SD in $\mathrm{mg} / \mathrm{kg}$ of milk) obtained by a direct analysis of milk samples by inductively coupled plasma atomic emission spectroscopy (ICP-AES) and by ICP-AES after mineralization ${ }^{1}$

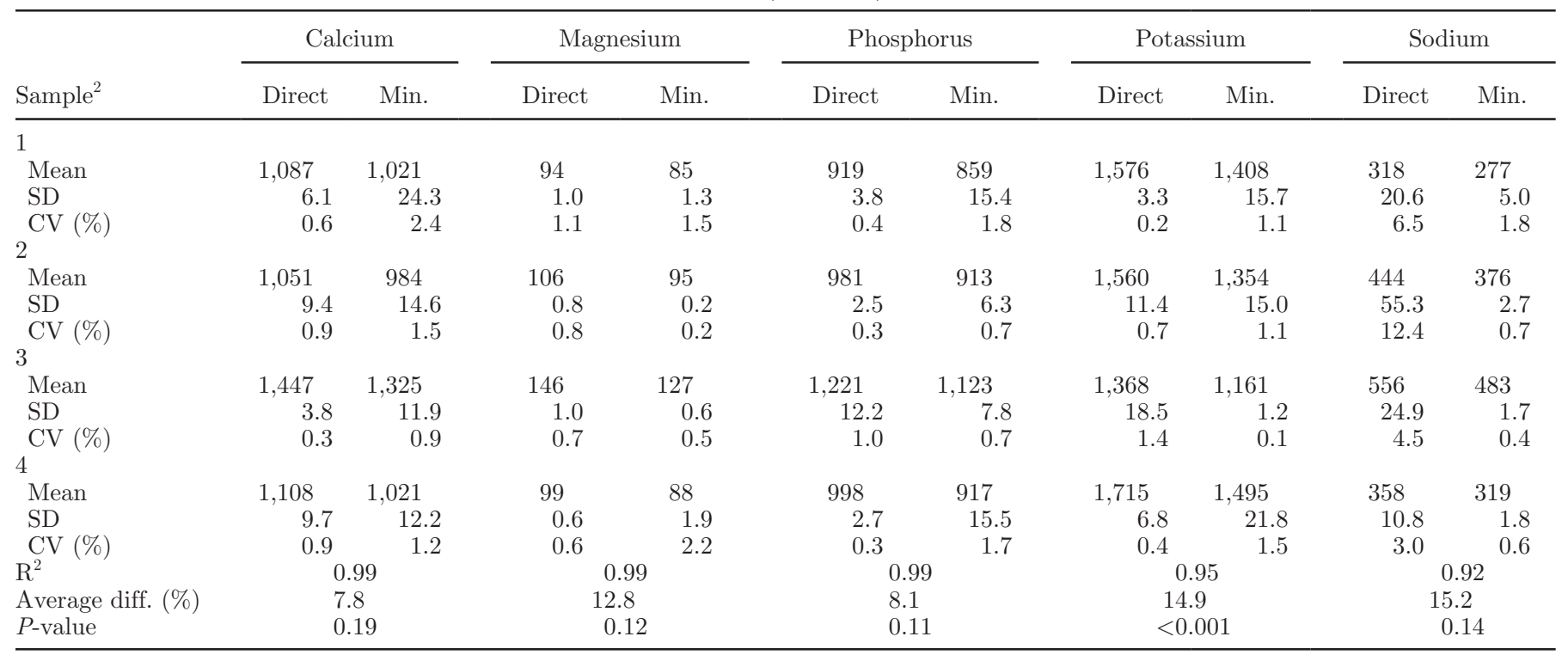

${ }^{1}$ Direct $=$ direct analysis of milk sample by ICP-AES; Min. = analysis of milk sample by ICP-AES after mineralization.

${ }^{2}$ The 4 samples were analyzed 3 times each. $\mathrm{R}^{2}=$ coefficient of determination for the relation between the contents measured by the direct ICPAES analysis and the contents measured by ICP-AES after mineralization; Average diff. = average difference; $P$-value $=P$-value for the test of equality of means.

mineralization. In this study, the measurement of $\mathrm{Na}$ by the two proposed methods did not provide similar results.

Based on the obtained results and the fact that the use of the ICP-AES with a previous mineralization stage increases the possibility of sample loss, direct analysis of milk sample by ICP-AES without mineralization was used to quantify the reference mineral contents needed for the development of calibration equations.

\section{Sample Selection}

Figure 1 illustrates the spectral variability of the 1,543 collected milk samples. All spectra were plotted and the variation is clearly observable. For convenience, the standard deviation for each spectral data points (1,060 in total for the spectra generated by the MilkoScan FT6000) is also represented. For financial reasons, it was not possible to analyze all collected samples. Principal components analysis was applied to select the most interesting samples to elaborate the first and second calibration sets. Thirty-one principal components described $99.98 \%$ of the spectral variability. As explained in the Materials and Methods section, a total of 100 milk samples were selected and 57 of the selected samples showing the largest spectral variability were analyzed by ICP-AES.
After ICP-AES analysis of these samples, we observed that the variation of $\mathrm{Ca}$ content was not completely represented, especially for the highest and lowest contents (Figure 2). Instead of the analysis of the remaining selected samples, we decided to apply the Ca calibration equation developed from the 57 analyzed samples to select samples permitting to complete the observed variation of $\mathrm{Ca}$ content. Figure 3 presents the predictions of $\mathrm{Ca}$ content for the 1,473 collected samples. A total of 30 milk samples showing the highest and lowest Ca contents was selected to be analyzed by ICP-AES and constituted the third calibration set.

\section{Reference Samples}

The descriptive statistics for the 3 calibration sets containing 92 samples are described in Table 2. Because of technical issues, the contents of $\mathrm{K}$ and $\mathrm{Mg}$ were not measured for the second calibration set by ICP-AES.

The total variation ranges observed for $\mathrm{Ca}, \mathrm{Na}$, and $\mathrm{P}$ from the 92 analyzed milk samples were 1,043, 561, and $505 \mathrm{mg} / \mathrm{kg}$ of milk, respectively. The total variation ranges observed for $\mathrm{K}$ and $\mathrm{Mg}$ from 62 samples were 80 and $767 \mathrm{mg} / \mathrm{kg}$ of milk, respectively (Table 2). The largest variability for the samples selected based on their spectral variability (calibration sets 1 and 2) was obtained for calcium, which was expected because 


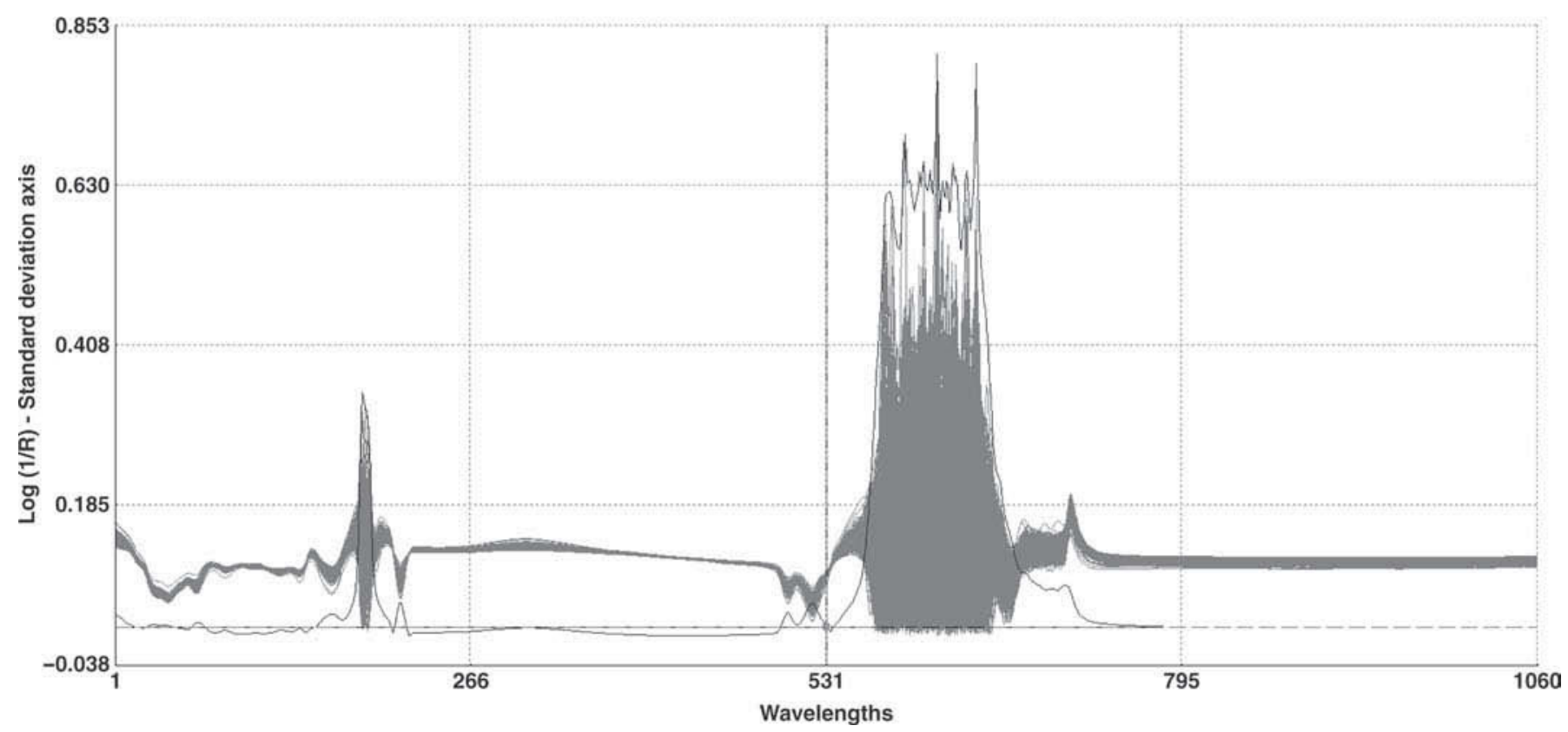

Figure 1. Spectral variability of the 1,543 collected milk samples. The gray background represents the spectral variability of the collected samples (all spectra are plotted). The continuous black line presents the standard deviation for the 1,060 spectral data points.

calcium showed also the greatest content in bovine milk (Table 2).

\section{Uncertainty}

Table 3 shows the uncertainty of the method used to measure the reference mineral contents. The highest uncertainty came from the recuperation percentage of mineral element in the CRM sample. The second highest contributors to uncertainty were related to the weighing of sample and to the purity of the CRM sample used. The total uncertainty ranged between 3.95 and $5.55 \%$ (Table 3 ). These values were globally $<5 \%$ and were, therefore, acceptable.

\section{Calibration Equations}

Table 4 depicts the descriptive statistics for the developed calibration equations. As explained previously, 3 distinct sets of calibration samples were analyzed. The first calibration equations, which quantified the $\mathrm{Ca}, \mathrm{K}, \mathrm{Mg}, \mathrm{Na}$, and $\mathrm{P}$ in milk, were built from 32 samples selected based on their spectral variability. The $\mathrm{R}^{2} \mathrm{c}$ values for the equations of $\mathrm{Ca}, \mathrm{Na}$, and $\mathrm{P}$ were $>0.80$. The cross-validation gave lowest values: $R^{2} \mathrm{cv}$ values for these equations were $>0.70$ and $R P D$ was $>2$. These statistics (RPD and $\mathrm{R}^{2} \mathrm{cv}$ ) observed for $\mathrm{Mg}$ and $\mathrm{K}$ were too low to investigate potential use of these equations.
The second step of this study was to establish calibration equations by the addition of the samples analyzed in the second calibration set. Table 4 presents the statistics of the developed equations for $\mathrm{Ca}, \mathrm{Na}$, and $\mathrm{P}$ from a total of 57 reference samples analyzed by ICPAES. The observed $\mathrm{R}^{2} \mathrm{cv}$ was higher compared with the first calibration equation only for the $\mathrm{Ca}$, even if the $\mathrm{R}^{2} \mathrm{c}$ was lower. The larger variation range of the second calibration set compared with the first calibration set could explain this difference (Table 2). The external validation for the developed equations was executed from milk samples contained in the third calibration set (Table 2). The $\mathrm{R}^{2} \mathrm{v}$ values were $0.97,0.14$, and 0.88 for $\mathrm{Ca}, \mathrm{Na}$, and $\mathrm{P}$, respectively (Figure 4). This external validation showed a poorer ability to predict $\mathrm{Na}$ using MIR spectrometry. However, these results showed the feasibility of using the developed calibration equations to predict the contents of $\mathrm{Ca}$ and $\mathrm{P}$ in milk.

Reference samples with extreme values of $\mathrm{Ca}$ were rare (Figure 2). Therefore, the samples for the third calibration set were selected based on their Ca MIR predictions obtained using the second $\mathrm{Ca}$ calibration equation to enhance the robustness of the prediction. The final step of this study was to rebuild the calibration equation for the total samples analyzed by ICP-AES. The RPD and $\mathrm{R}^{2} \mathrm{cv}$ values calculated for the calibration equations that predicted the contents of $\mathrm{Ca}$ and $\mathrm{P}$ were the highest (Table 4 ). Therefore, the addition of samples with extreme values of Ca improved the 


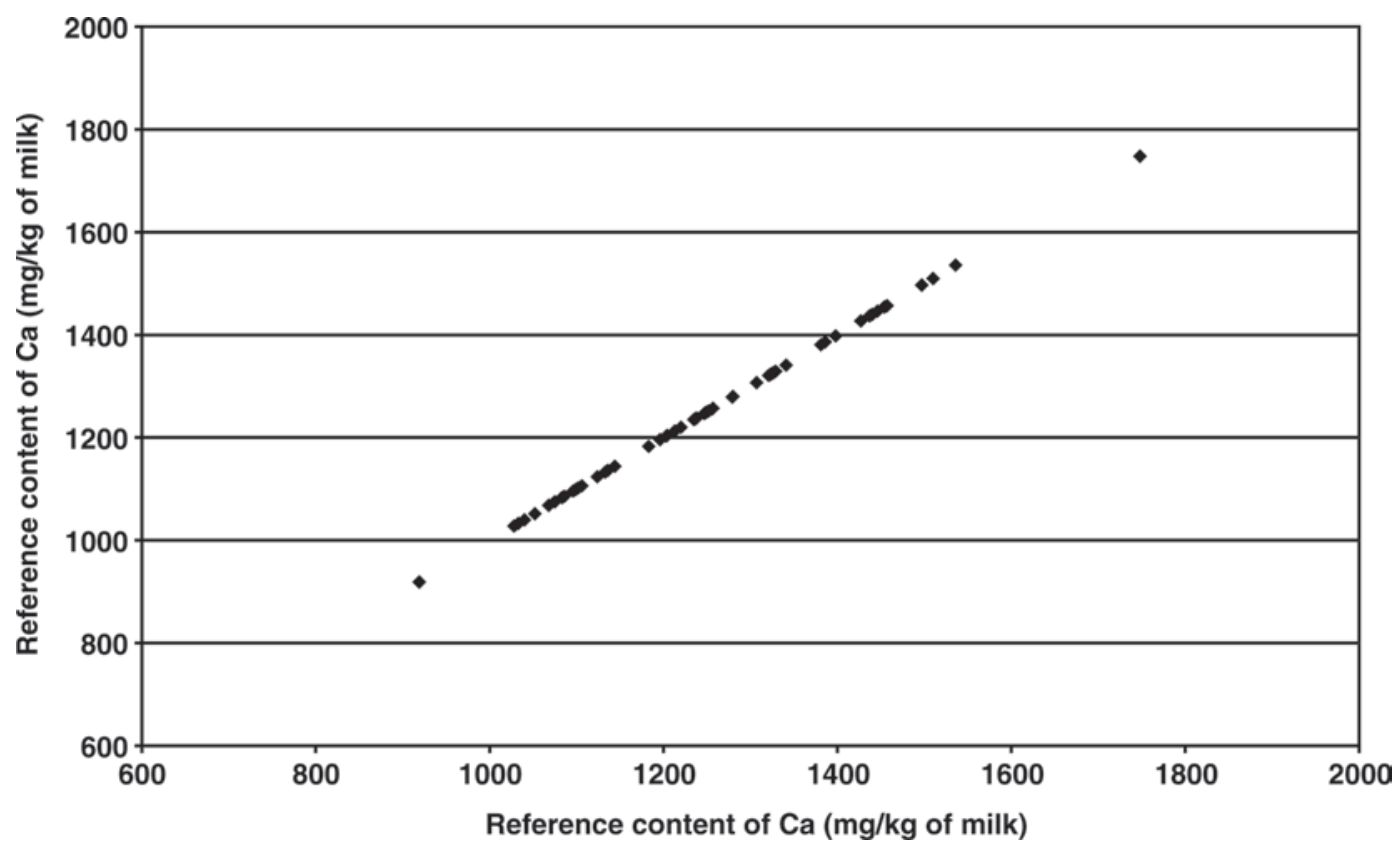

Figure 2. Reference calcium contents measured by inductively coupled plasma atomic emission spectroscopy from the 57 samples initially selected.

accuracy of the prediction $(\mathrm{RPD}=2.74)$. Perhaps the accuracy for the prediction of $\mathrm{P}$ by MIR spectrometry was improved $(\mathrm{RPD}=2.54)$ because of the positive correlation between $\mathrm{P}$ and $\mathrm{Ca}$ (0.73; Table 5). Even if selection of the reference samples used for calibration based on the spectral data is the best way to select the first samples, the selection of new samples based on the prediction given by an appropriate calibration equation seems to be the best way to improve the robustness of the calibration equation. Greater values of $\mathrm{R}^{2} \mathrm{cv}$ and $\mathrm{RPD}$ for $\mathrm{K}$ and $\mathrm{Mg}$ were also observed but the values were too low to investigate a potential

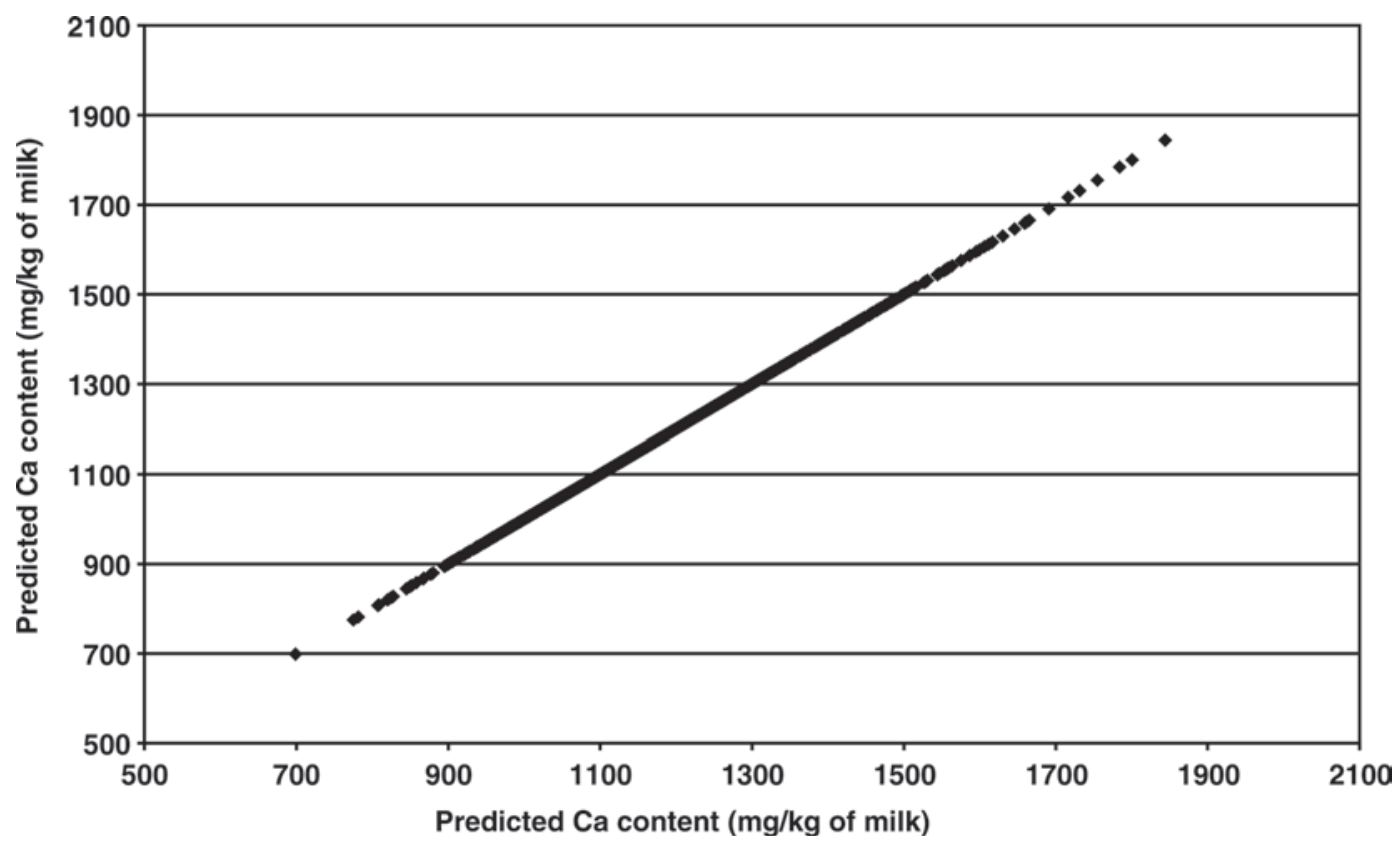

Figure 3. Calcium contents predicted by mid-infrared spectrometry using the calibration equation of calcium developed from 57 samples. 
use of these equations. However, the improvement of the prediction for $\mathrm{Mg}$ showed potential to increase the number of reference samples used to build this equation. These samples could be chosen using the second calibration equation established for $\mathrm{Mg}$. The decrease in the robustness of the equation predicting the content of $\mathrm{Na}$ could be partly explained by the chemical analysis used to measure the $\mathrm{Na}$ content. Based on the results presented in Table 1, direct analysis of milk by ICP-AES was less appropriate to measure the contents of Na. The contents of $\mathrm{Na}$ should be measured again using the ICP-AES with a mineralization stage. As the calibration equations are directly affected by the reference values, this might improve the robustness of this equation.

Usefulness of the developed equations exists only if the MIR predictions of minerals are related to a real spectral absorbance and cannot be estimated based on the correlations with other known milk components also predicted by MIR. In the Walloon milk recording, the contents of fat, protein, urea, and lactose are measured by MIR. The correlations between the $\mathrm{Ca}$ and $\mathrm{P}$ MIR predictions and the known milk components were calculated and shown in Table 5. All correlations were inferior to the correlation calculated based on the cross-validation. Therefore, the calibration equations established to predict the contents of $\mathrm{Ca}$ and $\mathrm{P}$ in bovine milk are useful because they came from a real spectral absorbance.

According to Williams (2007), calibration equations showing $\mathrm{R}^{2}$ values between 0.83 and 0.90 can be used with caution for most applications, including research. In conclusion, based on the obtained statistical parameters, this study showed the feasibility of quantifying the contents of $\mathrm{Ca}$ and $\mathrm{P}$ directly in milk using MIR spectrometry. This application could have interesting potential interest for dairy farmers. For instance, Harmon (1994) suggested that the variation of minerals in milk could be studied to detect the presence of mastitis.

\section{Interpretation of Calibration Equations}

The correlations between $\mathrm{Ca}$ and $\mathrm{P}$ contents and spectral data were also estimated to detect the most related spectral zones to mineral predictions by MIR. The greatest correlations for Ca were located between 1,454 and $1,458 \mathrm{~cm}^{-1}(\mathrm{R}=0.74)$ and between 2,831 and $2,970 \mathrm{~cm}^{-1}(\mathrm{R}=0.73)$. The greatest correlations for $\mathrm{P}$ were located between 1,200 and $1,277 \mathrm{~cm}^{-1}(\mathrm{R}=$ 0.77 ), between 2,841 and $2,974 \mathrm{~cm}^{-1}$ with a maximum at $2,974 \mathrm{~cm}^{-1}(\mathrm{R}=0.77)$, and between 1,442 and 1,469 $\mathrm{cm}^{-1}(\mathrm{R}=0.71)$. The spectral data located at 2,927 $\mathrm{cm}^{-1}$ and $2,858 \mathrm{~cm}^{-1}$ are related to milk fat. Conse- 
Table 3. Uncertainty of samples analyzed by inductively coupled plasma atomic emission spectroscopy (ICPAES) without mineralization stage

\begin{tabular}{lccccc}
\hline Source of uncertainty $(\%)$ & Calcium & Magnesium & Phosphorus & Potassium & Sodium \\
\hline Repeatability & 1.92 & 1.35 & 1.83 & 2.52 & 1.81 \\
Recuperation & 4.94 & 3.21 & 3.32 & 3.48 & 1.02 \\
Weighting & 1.02 & 1.02 & 1.02 & 0.01 & 1.02 \\
Dilution & 0.01 & 0.01 & 0.01 & 0.01 \\
ICP-AES & 0.69 & 1.05 & 0.56 & 0.36 & 0.18 \\
Stock solution & 0.30 & 0.18 & 0.62 & 0.56 & 0.69 \\
Dilutions of standard & 0.62 & 0.92 & 1.35 & 1.24 & 0.82 \\
Purity of CRM & 0.86 & 2.19 & 4.25 & 5.02 & 3.95 \\
Total uncertainty & 5.55 & 4.47 & & \\
\hline
\end{tabular}

${ }^{1} \mathrm{CRM}=$ certified reference milk (Community Bureau of Reference, Brussels, Belgium).

quently, the MIR predictions of $\mathrm{Ca}$ and $\mathrm{P}$ are linked to the content of fat, which was expected because the correlations between $\mathrm{Ca}$ or $\mathrm{P}$ and fat were positive (Table 5). The greatest correlations observed between 1,743 and $1,747 \mathrm{~cm}^{-1}$ were related to the carbonyl group of ester bonds present in milk fat and organic acid. The spectral zone between 1,446 and $1,470 \mathrm{~cm}^{-1}$ is characterized by $\mathrm{CH}_{2}$ and $\mathrm{CH}_{3}$ groups present in milk fat and proteins (Coates, 2000). The high correlation located at $1,242 \mathrm{~cm}^{-1}$ is related to the $\mathrm{P}=\mathrm{O}$ bond present in phospholipids (Bertrand and Dufour, 2006). The spectral zones known between $\mathrm{Ca}$ and the carboxylate group of casein at 1,410 $\mathrm{cm}^{-1}$ and $1,575 \mathrm{~cm}^{-1}$ (Byler and Farrell, 1989) did not show high correlation $(\mathrm{R}=0.46$ and $\mathrm{R}=$ 0.41, respectively). Upreti and Metzger (2006) studied the feasibility of developing calibration equations to measure organic $\mathrm{P}$ and bound $\mathrm{Ca}$ in Cheddar cheese. These authors based on the previous work of Fernandez et al. (2003) limited the development of calibration equations to spectral data between 1,050 and $900 \mathrm{~cm}^{-1}$.
In this region, Upreti and Metzger (2006) observed a region from 956 to $946 \mathrm{~cm}^{-1}$ related to the concentration of organic P. The region located around 980 $\mathrm{cm}^{-1}$ observed by those authors seemed to be related to bound Ca. In our study, these regions were not the most interesting for the measurement of $\mathrm{Ca}$ and $\mathrm{P}$ by MIR spectrometry.

\section{CONCLUSIONS}

This study showed the feasibility of predicting the contents of Ca and P by MIR spectrometry. The results obtained for the calibration equations that predict the $\mathrm{Mg}$ content indicated the need to increase the number of reference samples analyzed by ICP-AES used for the calibration procedure. The method used to measure mineral content (ICP-AES without mineralization) was inappropriate to determine the $\mathrm{Na}$ concentration in milk. As the calibration equations are strongly influenced by the reference values used, this inability could

Table 4. Statistics ${ }^{1}$ for the calibration equations developed for the prediction of $\mathrm{Ca}, \mathrm{Na}, \mathrm{P}, \mathrm{K}$, and $\mathrm{Mg}$

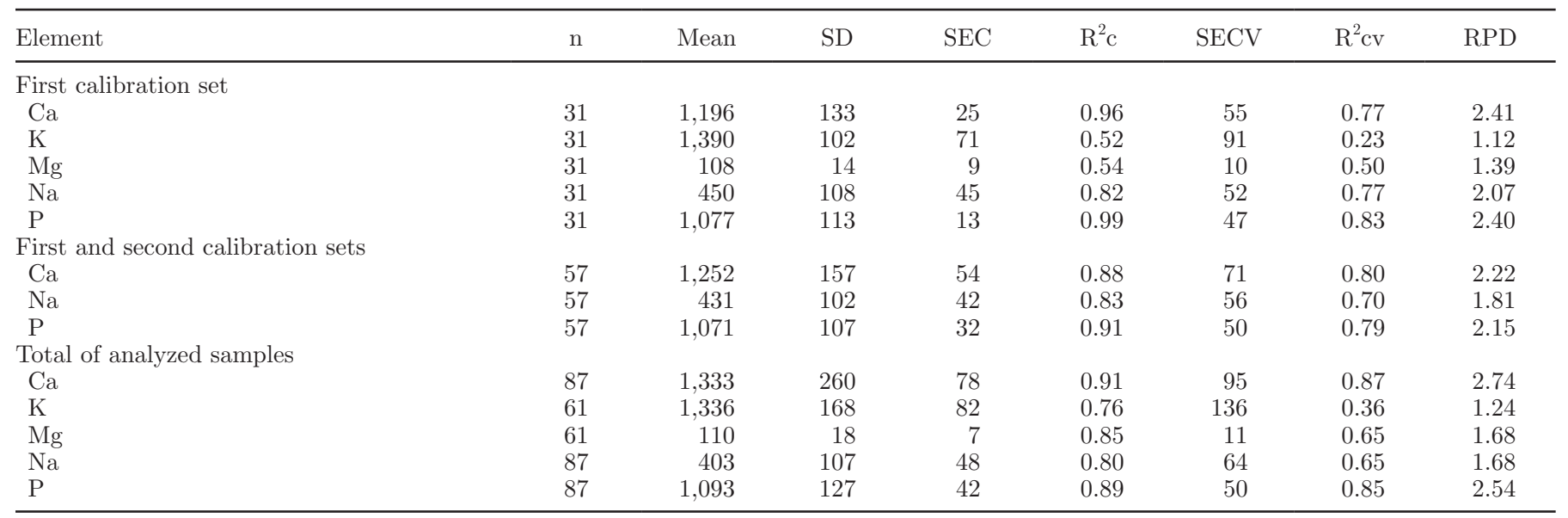

${ }^{1} \mathrm{SEC}=$ standard error of calibration; $\mathrm{R}^{2} \mathrm{c}=$ calibration coefficient of determination; $\mathrm{SECV}=$ standard error of cross-validation; $\mathrm{R}^{2} \mathrm{cv}=\mathrm{cross}-$ validation coefficient of determination; $\mathrm{RPD}=$ ratio of $\mathrm{SD}$ to SECV. 
a)

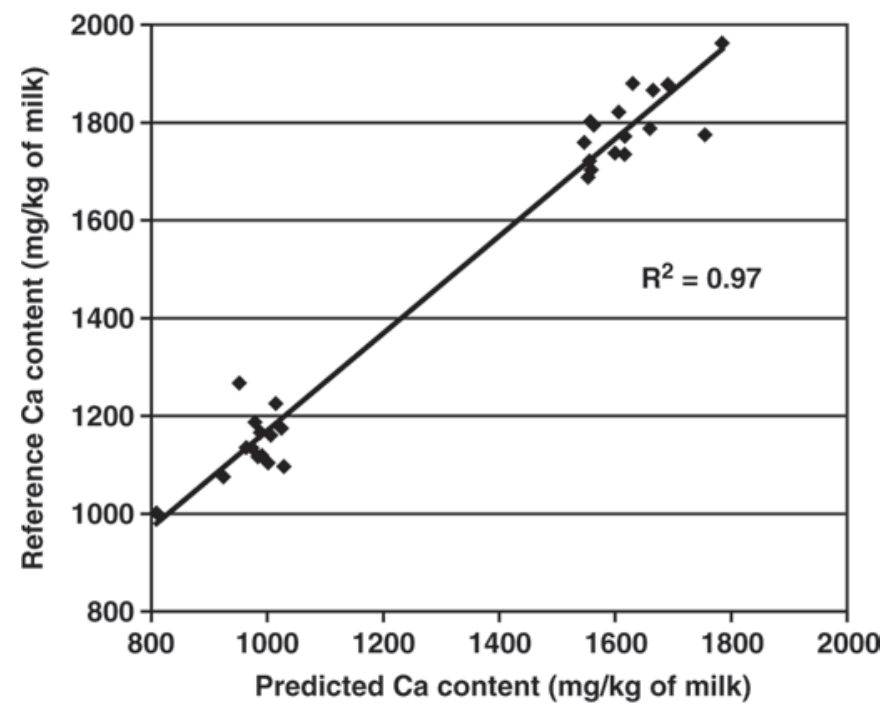

b)

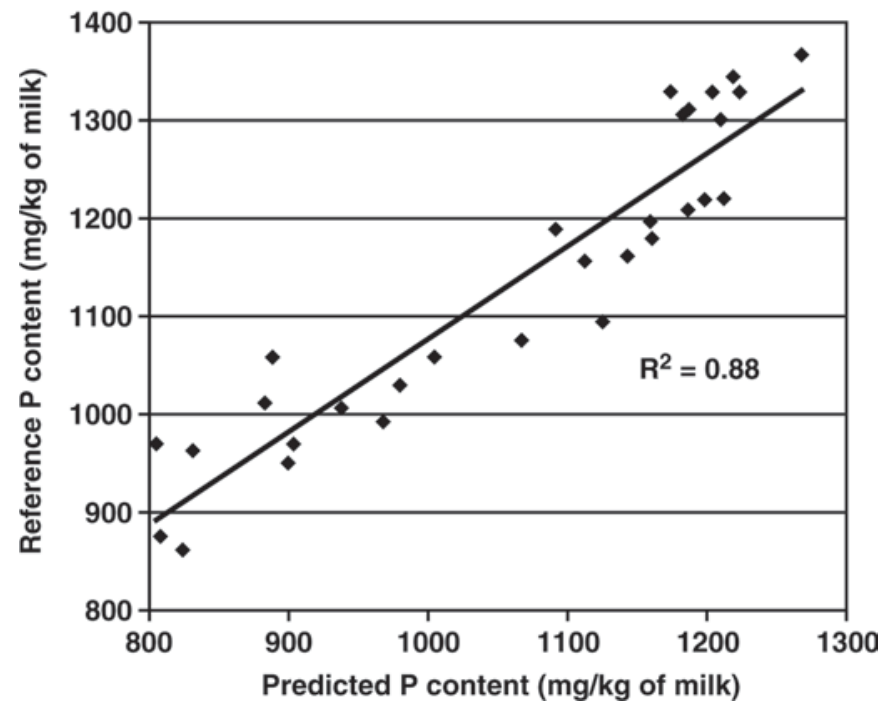

Figure 4. Relation between the reference contents of calcium and phosphorus measured by inductively coupled plasma atomic emission spectroscopy and prediction of $\mathrm{Ca}$ and $\mathrm{P}$ by mid-infrared spectrometry using the second calibration equation established for $\mathrm{Ca}$ and $\mathrm{P}$ for the samples selected for the third calibration set.

partly explain the poor prediction by MIR observed for this mineral. Finally, the prediction of K by MIR was not possible.

As MIR spectrometry is used routinely by the milk labs to estimate the contents of the major milk components such as the percentage of fat and protein (used for milk payment and milk recording), implementation of the developed equations to estimate the concentrations of $\mathrm{Ca}$ and $\mathrm{P}$ in milk could be interesting for dairy farmers to give added value to the produced milk and to improve cheese properties.
Table 5. Correlations between the contents of $\mathrm{Ca}$ and $\mathrm{P}$ measured by inductively coupled plasma atomic emission spectroscopy (ICPAES) and the known milk components predicted by mid-infrared spectrometry (contents of fat, protein, urea, and lactose)

\begin{tabular}{lrc}
\hline Component & Calcium & Phosphorus \\
\hline Phosphorus (mg/kg of milk) & 0.73 & \\
Percentage fat (g/dL of milk) & 0.72 & 0.62 \\
Percentage protein (g/dL of milk) & 0.64 & 0.70 \\
Percentage lactose (g/dL of milk) & 0.25 & 0.19 \\
Urea (mg/kg of milk) & -0.22 & -0.02 \\
Correlation of cross-validation & 0.93 & 0.92 \\
\hline
\end{tabular}

\section{ACKNOWLEDGMENTS}

The authors acknowledge the financial support provided through grants $2.4507 .02 \mathrm{~F}$ (2), F.4552.05, and 2.4623.08 of the National Fund for Scientific Research (Brussels, Belgium). Nicolas Gengler, research associate at the National Fund for Scientific Research (Brussels, Belgium) acknowledges its support.

\section{REFERENCES}

Bertrand, D., and E. Dufour. 2006. La Spectroscopie Infrarouge et Ses Applications Analytiques. 2nd ed. Lavoisier Tec et Doc, Paris, France.

Byler, D. M., and H. M. Farrell. 1989. Infrared spectroscopic evidence for calcium ion interaction with carboxylate groups of casein. J. Dairy Sci. 72:1719-1723.

Cerbulis, J., and H. M. Farrell. 1976. Composition of the milks of dairy cattle. II. Ash, calcium, magnesium, and phosphorus. J. Dairy Sci. 59:589-593.

Coates, J. 2000. Interpretation of infrared spectra, a practical approach. Pages 10815-10837 in Encyclopedia of Analytical Chemistry. R. A. Meyers, ed. John Wiley \& Sons, New York, NY.

Davis, S. R., V. C. Farr, S. O. Knowles, J. Lee, E. S. Kolver, and M. J. Auldist. 2001. Sources of variation in milk calcium content. Aust. J. Dairy Technol. 56:156.

Devriese, S., I. Huybrechts, M. Moreau, and H. Van Oyen. 2006. Enquête de consommation alimentaire Belge A - 2004. Institut Scientifique de Santé Publique. ISP/EPI Reports. http://www. iph.fgov.be/epidemio/epifr/foodfr/table04.htm. Accessed Sep. 2, 2008.

Fernandez, C., S. F. Ausar, R. G. Badini, L. F. Castagna, I. D. Bianco, and D. M. Beltramo. 2003. An FTIR spectroscopy study of the interaction between alpha s-casein-bound phosphosyryl group and chitosan. Int. Dairy J. 13:897-901.

Frank, I. E., J. Feikema, N. Constantine, and B. R. Kowalski. 1984 Prediction of product quality from spectral data using the partial least-squares method. J. Chem. Inf. Comput. Sci. 24:20-24.

Gerrior, S., and L. Bente. 2002. Nutrient content of the US food supply, 1909-1999: A summary report. Center for Nutrition Policy and Promotion, USDA, Washington, DC.

Guéguen, L., and A. Pointillart. 2000. The bioavailability of dietary calcium. J. Am. Coll. Nutr. 19:119S-136S.

Harmon, R. J. 1994. Physiology of mastitis and factors affecting somatic cell counts. J. Dairy Sci. 77:2103-2112.

Heaney, R. P. 2000. Calcium, dairy products and osteoporosis. J. Am. Coll. Nutr. 19:83S-99S

Huth, P. J., D. B. DiRienzo, and G. D. Miller. 2006. Major scientific advances with dairy foods in nutrition and health. J. Dairy Sci. $89: 1207-1221$

International Committee for Animal Recording. 2004. Section 2. ICAR rules, standards and guidelines for dairy production recording. http://www.icar.org/docs/Rules\%20and\%20regulations/ 
Guidelines/Guidelines_2005_final_low_resolution.pdf Accessed Nov. 17, 2005.

Lanou, A. J., S. E. Berkow, and N. D. Barnard. 2005. Calcium, dairy products, and bone health in children and young adults: A reevaluation of the evidence. Pediatrics 115:736-743.

Martens, H., and S. A. Jensen. 1982. Partial least squares regression: A new two-stage NIR calibration method. Pages 607-647 in Proc. 7th World Cereal and Bread Congress, Prague. K. Holas, ed. Elsevier, Amsterdam, the Netherlands.

Martens, H., and T. Naes. 1987. Multivariate Calibration by Data Compression. Wiley, Chichester, UK.

Mouillet, L., F. M. Luquet, and J. Casalis. 1975. Contribution à l'étude des variations de la teneur en sels minéraux du lait de vache dans différentes regions françaises. Lait 55:683-694.

Murcia, M. A., A. Vera, M. Martinez-Tome, A. Munoz, M. HernandezCordoba, and R. Ortiz-Gonzalez. 1999. Fast determination of the $\mathrm{Ca}, \mathrm{Mg}, \mathrm{K}, \mathrm{Na}$ and $\mathrm{Zn}$ contents in milk and non-dairy imitation milk using ICP-AES without mineralization stage. Lebens. Wiss. Technol. 32:175-179.
Nobrega, J. A., Y. Gelinas, A. Krushevska, and R. M. Barnes. 1997. Direct determination of major and trace elements in milk by inductively coupled plasma atomic emission and mass spectrometry. J. Anal. At. Spectrom. 12:1243-1246.

Roulez, D. 2001. Contribution à la mise en service d'un spectromètre d'émission atomique couplé à un plasma induit : Études de diverses matrices. MS thesis. Haute Ecole Charleroi-Europe, Charleroi, Belgium.

Skoog, D. A., D. M. West, and F. J. Holler. 1997. Chimie Analytique. 7th ed. De Boeck Université, Brussels, Belgium.

Upreti, P., and L. E. Metzger. 2006. Utilization of Fourier transform infrared spectroscopy for measurement of organic phosphorus and bound calcium in Cheddar cheese. J. Dairy Sci. 89:1926-1937.

Westerhaus, M. O. 1990. Improving repeatability of NIR calibrations across instruments. Pages 671-674 in Proc. 3rd Int. Conf. Near Infrared Spectroscopy, Brussels, Belgium. Agricultural Research Centre, Gembloux, Belgium.

Williams, P. 2007. Near-infrared technology - Getting the best out of light. PDK Grain, Namaimo, Canada. 